\title{
José Enrique Rodó en tres ensayistas mexicanos: Carlos Fuentes, Carlos Monsiváis y Enrique Krauze
}

\author{
José Enrique Rodó \\ in three Mexican essayists: \\ Carlos Fuentes, Carlos Monsiváis and Enrique Krauze
}

\section{Belén Castro Morales*}

Resumen: En este trabajo se analizan las opiniones de tres notables escritores mexicanos sobre la aportación de José Enrique Rodó al pensamiento latinoamericano contemporáneo. El corpus del trabajo está formado básicamente por el prólogo de Carlos Fuentes a la edición en lengua inglesa de Ariel (1988), el ensayo Aires de familia (2000) de Carlos Monsiváis, y el estudio histórico de Enrique Krauze "José Enrique Rodó", incluido en su libro Redentores (2011). Su lectura nos permitirá comprobar la difícil supervivencia del arielismo en las tempestades críticas de nuestro tiempo y en el México contemporáneo.

Palabras clave: José Enrique Rodó, Arielismo, Identidad, Carlos Fuentes, Carlos Monsiváis, Enrique Krauze.

ABSTRACT: This paper looks into the opinions of three outstanding XXth century Mexican writers on the contribution of Jose Enrique Rodó to contemporary Latin American thought. The corpus studied is basically the prologue of Carlos Fuentes for the English edition of Ariel (1988), the essay Aires de familia (2000) written by Carlos Monsiváis, and Enrique Krauze's "Jose Enrique Rodó" (in Redentores, 2011). The text will help us understand the hardships arielism has endured in contemporary Mexico in a thrust to survive in the turmoil of contemporary literary criticism.

Key words: José Enrique Rodó, Arielism, Identity, Carlos Fuentes, Carlos Monsiváis, Enrique Krauze.

Recibido: 22 de febrero de 2018

Aceptado: 23 abril de 2018

Universidad de La Laguna, Tenerife, España(mbcastro@ull.edu.es). 


\section{INTRODUCCIÓN}

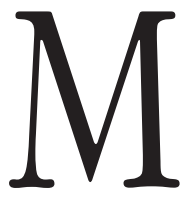

ás allá de los primeros ecos que suscitaron los grandes ensayos de José Enrique Rodó Ariel (1900) y Motivos de Proteo (1909) en los jóvenes ateneístas mexicanos, en este trabajo se aborda la presencia de su ideario latinoamericanista en otros ensayos contemporáneos, con el doble propósito de comprobar cómo ha sobrevivido el legado humanista de Rodó en el cambio de milenio y mostrar cómo estos intelectuales mexicanos han ido situando su posición enunciativa transcurrido un siglo; es decir, desde el horizonte neoidealista de la Modernidad de 1900, cuando Rodó dedicó su Ariel a la juventud de América, hasta la profunda quiebra de esa idea de Modernidad ilustrada, que el mismo Rodó llegó a profetizar ante la barbarie que desató en Europa la Gran Guerra de 1914. ${ }^{1}$

Supuso un acicate para decidir este enfoque la relectura del breve artículo de Leopoldo Zea, "Ariel, un siglo después" (2002), donde el filósofo mexicano seguía sosteniendo con vehemencia el sentido visionario y profético de Rodó ante los profundos cambios e incertidumbres que amenazaban a la "Magna Patria" latinoamericana. En su panorama presentaba la transformación del orden mundial bipolar, vigente hasta el final de la Guerra Fría, en un nuevo orden multipolar, dominado por la emergencia de las potencias asiáticas, por el neoliberalismo y la despiadada competencia entre los mercados multinacionales por el control del capital. Jugando con los personajes-metáfora de La tempestad de Shakespeare que Rodó reactualizó en Ariel, Zea observaba que el materialista Calibán se había aliado con el mago Próspero y servía a su ilimitado poder científico y tecnológico, ya deslocalizado y globalizado, mientras nuevos peligros

1 En el artículo "La tradición de los pueblos hispanoamericanos" (1915) Rodó cuestiona la tesis ilustrada de Condorcet sobre la Modernidad como un "progreso indefinido", y critica la imitación de los modelos europeos que él mismo había propuesto como una fase de dependencia necesaria: "De [esa imitación] procede nuestro permanente desasosiego, lo efímero y precario de nuestras funciones políticas, el superficial arraigo de nuestra cultura" (Rodó 1967: 1204). 
se cernían sobre las periferias frágiles del Sur, antes colonizadas por la Europa Occidental, y ahora (en el caso de México) asociadas con Estados Unidos mediante tratados internacionales como el Tratado de Libre Comercio (TLCAN), con la consiguiente amenaza para su integridad política y cultural. ${ }^{2}$ En su análisis económico y moral de estas crudas realidades "posthistóricas", Leopoldo Zea recurría a argumentos éticos para salvaguardar la identidad de América Latina como una reserva de la cultura humanística y una forma de resistencia:

¿Qué tenemos que hacer nosotros los marginados y bárbaros para enfrentar la misma e insistente política de dominio de las naciones que se empeñan en serlo? Tenemos esa maravillosa herencia, ese pleno y auténtico humanismo que nos legaron tantos soñadores de nuestras tierras. La Nación de naciones, la Raza de razas, el pasado multirracial y multicultural de cuyo origen e historia nos habla José Enrique Rodó (2002: 11).

Pero la unidad y la confraternidad intelectual que postulaba Rodó como una estrategia de resistencia supranacional frente a la deslatinización de las nuevas democracias, ¿seguirá siendo suficiente en el siglo XXI? Como veremos, ninguno de los autores que analizaremos aquí se proclama explícitamente "arielista" o "neoarielista", como sí lo ha hecho el profesor chileno Grínor Rojo; ${ }^{3}$ sin embargo, ninguno de ellos duda en reconocer un vínculo más o menos lejano con Rodó, ni en señalarlo como el pionero en oponer un proyecto cultural identitario al imperialismo y a la influencia materialista de Estados Unidos.

Como es sabido, desde su posición liberal y neoidealista, Rodó no formuló soluciones políticas específicas, ni recetas de economía, sino algo

2 Véase también el panorama que había ofrecido Carlos Fuentes en su conferencia "Después de la Guerra Fría: los problemas del nuevo orden mundial" (1994), donde desarrolló con mayor amplitud el cuadro de transformaciones históricas y socioeconómicas.

3 Me refiero al libro de Grínor Rojo, Las armas de las letras. Ensayos neoarielistas (2008), donde su "neoarielismo" se define como una defensa del papel integrador de la educación estética y de las maltrechas Humanidades, así como del valor del intelectual como crítico de la sociedad tecnocrática. 
más importante: cuando el cientificismo positivista en que se educó asestaba el primer golpe a las Humanidades en los programas educativos, él defendió la cultura como el contrapeso imprescindible para el desarrollo armonioso de los individuos y como un lugar de reconocimiento de la sociedad en torno a unos ideales éticos y estéticos, pacifistas, solidarios e integradores. Los intelectuales de las nuevas democracias latinas, organizados en redes comunicativas como las que el mismo Rodó consiguió formar desde Montevideo, constituirían una élite orientadora destinada a iluminar el valor del "desinterés" y la trascendencia del pensamiento sobre la productividad material del trabajo especializado y alienante. Y así, por boca de un profesor llamado Próspero, Rodó indicaba la "luz de la inteligencia" de Ariel como el aura distintiva de las repúblicas del Sur, de la que carecían los nuevos fenicios y cartagineses del Norte.

Por esa elevación y flexibilidad de su discurso, el mensaje de Ariel se prestó a múltiples interpretaciones por parte de arielistas de muy variadas tendencias. Al mismo tiempo, la aceleración de la historia a lo largo del siglo xx ponía sobre la mesa de los intelectuales latinoamericanos nuevos problemas y desafíos que Rodó no llegó a vislumbrar en su diseño democrático (por un lado, otras formas de dominación neocolonial, nuevas revoluciones y dictaduras; por otro, el análisis científico del subdesarrollo, el feminismo, las reivindicaciones de las minorías étnicas y de género, la ecología, las iniciativas de la ciudadanía frente a los poderes instituidos). Algunas de estas preocupaciones, intensificadas con la posmodernidad, son las que nuestros autores, con distinto énfasis, proyectarán sobre el ensayo de Rodó para señalar sus aciertos, rectificar sus perspectivas o llenar sus silencios.

Al cerrar su prólogo a la versión angloamericana de Ariel (1988), Carlos Fuentes culminaba con esta síntesis, donde se concentran los sentimientos ambivalentes de un intelectual de finales del siglo xx hacia la obra casi centenaria de José Enrique Rodó:

Irritating, insufferable, admirable, stimulating, disappointing Rodó: our Uruguayan uncle, sitting in a corner of our family portrait, letting us became ourselves as we push him into the shadows, then realize that he has 
something to say yet: we give you the limelight again and then, old man, we bang you over the head again. So, you are part of our family quarrels and must bear with your disrespectful, equally disappointed, intuitive, incomplete nephews, living in a world that you helped define for us, and offered unto our revolt (Fuentes 1988: 26). ${ }^{4}$

En este prólogo, donde Fuentes abordó críticamente Ariel como el texto fundacional del pensamiento sobre la identidad latinoamericana, nos presenta un retrato de familia casi vacío, pues a través de esa énfrasis solo podemos ver al casi fantasmal y arrinconado Rodó (el viejo tío uruguayo) y a su sobrino irrespetuoso. Pero, iquiénes son los demás en ese retrato de familia? El autor de Terra Nostra parece invitarnos a participar en un juego de adivinaciones, y me arriesgo a suponer que integrarían el grupo otros intelectuales que pensaron el problema de la identidad latinoamericana. Así, difuminados al fondo podrían estar Simón Bolívar, Andrés Bello, Eugenio María de Hostos, José Martí; en un término medio, otros parientes más cercanos, como Samuel Ramos, Pedro Henríquez Ureña, Alfonso Reyes y José Vasconcelos; y en el primer término, algunos contemporáneos mexicanos como Octavio Paz, Leopoldo Zea y, quizás, Rosario Castellanos, Margo Glantz, Elena Poniatowska. En este juego, nada trivial (pues se trataría de decidir el canon del pensamiento latinoamericanista del siglo Xx) cada cual podrá recomponer ese retrato, ya sea a gran escala latinoamericana o a escala mexicana. Sin embargo, para este trabajo sólo he seleccionado a estos tres autores recientes que, en diversos formatos textuales, se ocuparon de situar a Rodó y el arielismo en el plano del debate contemporáneo: por orden cronológico, el mismo Carlos Fuentes, a través de este prólogo-ensayo en inglés; Carlos Monsiváis, con su ensa-

4 "Irritante, insufrible, admirable, estimulante, decepcionante Rodó: nuestro tío uruguayo, se sienta en una esquina de nuestro retrato de familia, nos permite ser nosotros mismos a la vez que le empujamos a las sombras y entonces nos damos cuenta de que todavía tiene algo que decir: te damos el protagonismo de nuevo y entonces, viejo, te golpeamos otra vez en la cabeza. Eres parte de nuestras disputas familiares y tienes que soportar a tus irrespetuosos sobrinos, igualmente decepcionados, intuitivos e incompletos, viviendo en un mundo que definiste para nosotros y que ofreciste a nuestra revuelta" (Fuentes 1988: 26). Traducción de la autora. 
yo "proteico" Aires de familia (2000), y Enrique Krauze, con su ensayo histórico "José Enrique Rodó", incluido en su libro Redentores (2011). Es obvio que estos textos, por su propia naturaleza discursiva, responden a distintas situaciones comunicativas y van dirigidos a lectores diversos, hecho que habría que tener en cuenta; pero los tres, como documentos ideologizados, no esquivan la significación de Rodó al reconsiderar el problema de la identidad cultural ante el porvenir de América Latina.

Por la amplitud descriptiva e informativa de su contenido, que conviene al orden de nuestra exposición, se analizará en primer lugar la contribución del historiador, editor y académico Enrique Krauze, titulada "José Enrique Rodó. La homilía hispanoamericana", aunque según el orden cronológico de publicación debería seguir a las de Carlos Fuentes y Carlos Monsiváis, con las que contrasta visiblemente por su enfoque académico y distanciado. Su autor —somos conscientes de ello-introduciría en el hipotético "retrato de familia" de Fuentes una presencia incómoda, dados sus fuertes desencuentros, ${ }^{5}$ pero por eso mismo aporta un necesario contrapunto.

Este trabajo (el más clásico y neutro también en su tono enunciativo) apareció publicado en su libro Redentores. Ideas y poder en América Latina (2011), y se lee en la primera parte, titulada "Cuatro profetas", entre el perfil de José Martí, y los de José Vasconcelos y José Carlos Mariátegui. ${ }^{6}$ Enrique Krauze enfoca la figura de Rodó como un intelectual formado en la idea europea de que existe un espíritu definidor de las naciones, impul-

5 La animadversión de Krauze hacia la obra y el pensamiento de Fuentes, con un momento álgido en 1988, puede notarse en algunos párrafos de Redentores, especialmente en su semblanza de Octavio Paz.

6 Los otros capítulos van dedicados a: (2) Octavio Paz, hombre en su siglo; (3) Íconos revolucionarios (Eva Perón, el Che Guevara); (4) Novela y política: Gabriel García Márquez y Mario Vargas Llosa; (5) Religión y rebelión: Samuel Ruiz (obispo de Chiapas) y el subcomandante Marcos; (6) Hugo Chávez, el caudillo posmoderno. 
sada por Fichte y Renan, así como en el culto al héroe de Carlyle, que inspiró su percepción heroica de Bolívar y modelaría también la concepción histórica de su discípulo arielista Francisco García Calderón. Con ese bagaje presenta a Rodó como "el primer ideólogo del nacionalismo hispanoamericano" (41) o del "nacionalismo latinoamericano", expresión algo ambigua que se clarifica cuando añade que se trata de "una apuesta continental, de raza y sangre, por encima de las fronteras [... concebida, como una hermandad irrenunciable" (59), opuesta a Estados Unidos. En otras palabras, el historiador se refiere a la idea de raíz bolivariana de esa supranacionalidad cultural y espiritual que Rodó llamó "Magna Patria", formada por la unión fraternal de las repúblicas que fueron colonias españolas.

Krauze analiza la significación profética de Ariel y afirma la originalidad y oportunidad de su aparición en 1900, por su planteamiento cultural e idealista que pronto derivó en el arielismo, divulgado desde Montevideo hacia distintos focos intelectuales del continente, a través de varias generaciones de "redentores" y revolucionarios de diversas y hasta opuestas ideologías. Su análisis se enmarca entre algunos trazos biográficos de Rodó: desde su formación en el convulso Uruguay del último cuarto del siglo XIX hasta su posterior consagración internacional como "Maestro de la juventud americana", sin omitir las decepciones que oscurecieron su ánimo por la ruina y la marginación con que el gobierno de José Batlle y Ordóñez pagó su independencia de criterio. Si en el enfoque biográfico sigue de cerca, sobre todo, la introducción de Emir Rodríguez Monegal a las Obras completas (Rodó: 1967), en la médula de su exposición Krauze enfoca la fuerza y el éxito internacional de Ariel a la luz de su propio concepto liberal de la historia de las ideologías políticas de América Latina, donde la figura de Rodó encarna las ideas del "redentor" o "santo laico" que con su singular celo apostólico y el arma de la palabra impresa, consiguió transmitir al siglo xx principios afirmativos de unidad cultural contra la penetración de Estados Unidos. Ante la dualidad conflictiva entre "redención o democracia" (16) que Krauze plantea al final de su prólogo, la figura de Rodó queda como suspendida en el limbo del héroe cultural de principios de siglo, que, aun admitiendo la fórmula democrática como la mejor para el 
gobierno de una república moderna, reclama la función dirigente de una minoría selecta.

Para explicar la novedad que supuso la crítica de Rodó a Estados Unidos a raíz de su intervención en la Guerra Hispano-Cubana de 1898 y de su consiguiente dominio sobre las últimas colonias españolas, Krauze empieza por describir en el marco histórico del siglo XIX la admiración que los liberales latinoamericanos le profesaban a Estados Unidos, pese a su creciente voracidad, desde que se apropiaron de más de la mitad del territorio de México en 1848 hasta el Desastre de 1898, sin excluir los pactos y desconfianzas que tensaron las relaciones entre México y Estados Unidos durante la república liberal de Benito Juárez y la prolongada dictadura de Porfirio Díaz. Ante estas evidencias ia qué se debía entonces esa fascinación por Estados Unidos que Martí llamó "yankimanía" y Rodó "nordomanía"? Krauze nos recuerda que la potencia del Norte había sido para esos liberales un modelo de democracia y de progreso, y que, incluso, había inspirado la primera constitución republicana de México (1824); pero, además, fue tierra de acogida para los liberales mexicanos exiliados durante los gobiernos de Santa-Anna y de Maximiliano I, y tampoco dejó de seducir a los sectores más progresistas del país por su eficacia en el desarrollo de la educación pública, como también sedujo a los "civilizadores" rioplatenses Sarmiento y Alberdi. Podemos añadir que incluso siguió deslumbrando a muchos demócratas republicanos que apoyaban la independencia cubana, al conocer su campaña contra la opresión de la monarquía española en la isla y la crueldad de las "reconcentraciones" de campesinos del Capitán General de Cuba, Valeriano Weyler.?

En su interesante discurso, "Ariel en el momento de su aparición" (1950), el escritor uruguayo Emilio Frugoni, político socialista amigo de Rodó, explicó esa visión positiva ("ariélica") que suscitaba EE.UU. en Uruguay poco antes de 1898: "Lo curioso es que el entusiasmo por Estados Unidos había prendido en el corazón de los jóvenes hispanoamericanos, no por el ascendiente de la grandeza material [...] sino por virtud del ademán de paladín de los derechos de un pueblo oprimido y de un sueño de independencia nacional, que la poderosa república del Norte había desplegado cuando hizo suya la gloriosa causa de 'Cuba Libre' y se encaró con la monarquía española para hacer triunfar las sagradas aspiraciones de los valientes 'filibusteros' cubanos" (1950: 207). 
Las crónicas que José Martí enviaba desde Nueva York, y en especial el clarividente ensayo "Nuestra América" (que se reprodujo el 31 de enero de 1891 en el diario El Partido Liberal de México) no lograban convencer del peligro que entrañaba "el gigante de siete leguas" con sus ansias de poder. Para el caso de México, Krauze sitúa esa toma de conciencia, en 1897, cuando Justo Sierra, que había sido amigo de Martí y conoció in situ su "formidable codicia" hacia Cuba, expresó su desencanto en su diario de viaje En tierra yankee. Ahí daba la razón a su amigo cubano, inmolado en 1895 durante su abordaje a la isla de Cuba. ${ }^{8}$ La intervención en la isla en 1898 consiguió mitigar la admiración hacia un país que ya enseñaba sin pudor su vocación imperialista. En esa lenta toma de conciencia, Rodó ofrecía con Ariel un ideario para cohesionar a una gran nación de naciones latinas, jóvenes y extraviadas respecto a su propio destino. En ese sentido recuerda con el krausista español Rafael Altamira que Ariel ofreció esperanzas de regeneración a la España vencida, como también infundió conciencia y valor a la América Latina ante el imperialismo.

Pero, ¿cómo forjar un sentimiento de identidad orgullosa y positiva cuando el atraso del vencido imperio español era tan evidente, frente al potencial anglosajón? Krauze explica que, a diferencia de la generación española del 98, que vio en Don Quijote el símbolo de un idealismo invicto, en Hispanoamérica se optó por adoptar los personajes de La Tempestad de Shakespeare (el espíritu Ariel, que ayuda al duque italiano Próspero cuando este naufraga en la isla del salvaje Calibán). En efecto, Don Quijote, "derrotado por la tecnología de los molinos" (Krauze 2011: 49), no convenía como símbolo de la identidad hispanoamericana, pero sí Ariel, que representaba más directamente el triunfo del espíritu sobre la mate-

8 Escribía Justo Sierra: "Lo que aquí hay es una formidable codicia; lo que aquí existe es el mismo cínico apetito que determinó al Congreso americano a aceptar la anexión de Texas [...] la verdad es que Cuba es un gran business [...] la preparación quedará completa en el curso de 98; entonces la amonestación amistosa a España se convertirá en aspérrima intimidación, y el coloso levantará su voz formidable para formular un ultimátum... una guerra por Cuba que empezará por hacer de Cuba misma la prenda pretoria, sería aquí enormemente popular" (Krauze 2011: 139). 
ria. ${ }^{9}$ Krauze revisa los antecedentes inmediatos de la contraposición Ariel (Hispanoamérica) versus Calibán (Angloamérica) a través de la comparación de los invasores con Calibán, que ya habían propuesto Paul Groussac en las impresiones de su viaje a Estados Unidos y Rubén Darío en su crónica "El triunfo de Calibán" (1898). Krauze advierte que Rodó no solo optó por focalizar su interés en el positivo Ariel, sino que el esquematismo que se atribuye a la contraposición Ariel/Calibán procede más de ciertas interpretaciones que del propio Rodó, que, ciertamente, matizó sus juicios sobre los angloamericanos y usó en su ensayo "la suavidad didáctica del filósofo pausado y reflexivo" (53). Concluye Krauze que, a diferencia de otras proclamas por la unidad de América Latina, "Ariel aportó la idea de la unidad cultural que, a la postre, sería la más activa, influyente y longeva. Y quizás la única que sigue viva" (53).

Krauze analiza también el criterio ponderado de Rodó frente al positivismo y su fe en la ciencia, pues no negaba su contribución al progreso material, sino su degeneración hacia actitudes utilitarias y materialistas. Además, el historiador hace notar que Rodó, a diferencia de otros contemporáneos, no suscribió las aplastantes teorías del racismo científico de Le Bon sobre la inferioridad racial de los pueblos mestizos que, unidas a su evidente atraso tecnológico, los destinaban al desgobierno, el subdesarrollo y la dependencia. ${ }^{10} \mathrm{Al}$ superar el determinismo racial, Rodó dibujaba un panorama donde era posible el progreso, siempre apoyado en el poder integrador de la educación, donde la superioridad cultural subvertiría la jerarquía Norte-Sur. "Nuestra aparente debilidad era nuestra fuerza" (55), afirma Krauze. A esto se suma que, al cuestionar Rodó la legitimidad de las tesis providencialistas del Destino Manifiesto (que justificaban la expansión territorial de Estados

9 Según Rubén Darío, Don Quijote se habría suicidado en Cuba en 1898, como propuso en aquel cuento trágico y patético titulado "D. Q", que escribió en Madrid en 1898 y publicó el Almanaque Peuser para el año 1899 (Buenos Aires: Peuser, 1898: 57-58).

10 La crítica más extensa de Rodó al positivismo aplicado en América (no al de sus "cumbres") se encuentra en "Rumbos nuevos" (1910), manifiesto generacional donde declaraba: "somos los neoidealistas" (1967: 497-507). Véase, sobre su crítica al determinismo racial, su rectificación a propósito del ensayo Pueblo enfermo, de Alcides Arguedas, en su carta a este autor (Rodó 1967: 1426-1428). 
Unidos), inició con Ariel un pensamiento descolonizador, en todo opuesto a la ideología colonialista e imperialista vigente en Europa y Angloamérica.

Así, a partir de Ariel, Krauze señala cómo intelectuales y políticos de signo ideológico muy distinto coincidirán en la importancia de la Universidad como fuente de saber y como un recurso más valioso para el progreso científico y moral que la mera posesión de riquezas materiales. Mientras la figura del maestro se enaltece, el verdadero redentor arielista no será (todavía) el proletario, sino el joven estudiante universitario que empezó a manifestarse en los movimientos de Reforma Universitaria, iniciados en Córdoba en 1918. Por eso Krauze dedica su atención a tres de sus ideólogos: los socialistas Alfredo Palacios, Manuel Ugarte y Deodoro Roca, defensor de los derechos humanos.

En resumen, Enrique Krauze hace derivar de Ariel dos vertientes principales:

En primer lugar, la superioridad de la cultura latina sobre el utilitarismo del Calibán del norte, pretensión que en algunos círculos se vuelve agresiva y militante: el hispanoamericanismo es también antiyanquismo. En segundo lugar, la idea de juventud como fuerza de la patria y, por lo tanto, la necesidad de la educación como recurso indispensable para alcanzar la altura del ideal (55).

Además, al analizar las razones de la expansión de Ariel, Krauze señala otros aspectos fundamentales del mensaje de Rodó: el propósito de "formar un ideal en la clase dirigente", recogido por Pedro Henríquez Ureña; "el despertar de la conciencia" y del sentimiento de una "fraternidad americana" que, según Alfonso Reyes, Rodó suscitó en su generación; y la salvación por la estética y la cultura, idea que "el caudillo cultural" José Vasconcelos, como Reyes, descubrió en Ariel. En efecto, el historiador trata a José Vasconcelos como uno de estos "redentores" que imprimió a esos principios arielistas de la unión latinoamericana y el antiimperialismo "una variación original y proteica" (91), mientras que, como educador y fundador de escuelas y bibliotecas, Vasconcelos fue un "Sarmiento mexicano" (141). Pero también recuerda Krauze que Vasconcelos introdujo su orientación indigenista (la lucha alegórica de Quetzalcóatl contra Huitzi- 
lopochtli) al presentar su fracasada cruzada a la presidencia en 1924, un año antes de escribir su "desorbitada fantasía" La raza cósmica (1925). De este ensayo, Krauze señala:

Vasconcelos lleva el mensaje de Ariel a un extremo delirante y anuncia el designio divino: seremos la cuna de la quinta raza, la definitiva, que fundirá los cuatro fragmentos raciales que habitan el planeta. Cerca del Amazonas se levantará la ciudad eterna, Universópolis, allí los hombres vivirán transidos de amor y belleza (91).

Como en su momento escribió Gonzalo Varela (2000) - aunque concediendo una valoración más positiva de la utopía de Vasconcelos- fue éste y no el propio Rodó, tan limitado en su praxis política, el que encarnó los verdaderos valores arielistas:

El intelectual ariélico por excelencia, cultivador de todas las facetas del espíritu - desde la acción política hasta la filosofía, pasando por la promoción de la educación popular- no es Rodó sino Vasconcelos, cuyo pensamiento coincide en gran medida con el del uruguayo (aunque sus elogios al mismo son parcos), incluso en el esteticismo y en la defensa de la aristocracia del mérito (Varela 2000: 82).

En estas páginas expositivas no se lee ninguna crítica explícita a las limitaciones o silencios del ensayo de Rodó, ni a la superación de su ideario por las vanguardias o el marxismo, pues el historiador, situado en el horizonte de 1900, no abarca sino los primeros ecos arielistas. Pero el lector suspicaz podrá echar en falta un énfasis mayor en las convicciones democráticas de Rodó (expresamente afirmadas en Ariel cuando disintió de su maestro, el antidemócrata Renan); o una revisión de la validez de algunos argumentos negativos de Rodó sobre Estados Unidos, en consonancia con esa posición antiyankee en la que Krauze señala una idea clave de Ariel y del arielismo. ${ }^{11}$

11 En "La invención de Ariel" (2003), el autor se refería al "rechazo casi ontológico" del arielismo a Estados Unidos, "siempre infructuoso y paralizante" en términos políticos y económicos (142). 
Muy distinto es el tono vehemente del prólogo para la traducción de Ariel al inglés, que Carlos Fuentes firmó en 1987 en la Universidad de Cambridge y publicó al año siguiente la Universidad de Texas en Austin, pese a que se trata de una edición didáctica destinada a estudiantes anglófonos. En su metafórico retrato como sobrino rebelde del apaleado Rodó, podemos verlo (como a su admirado Velázquez en Las Meninas) fuera y dentro del retrato: como un observador crítico y, a la vez, como personaje integrado en la composición. Así, con esa bifocalidad, podemos leer su prólogo como la nueva alocución de un ocasional y desenfadado profesor latino a los estudiantes estadounidenses, situado esta vez al otro lado de "la frontera de cristal" - hoy mucho menos cristalina y permeable que en 1988-, y en aulas y bibliotecas quizás frecuentadas por algunos dreamers mexicanos, amenazados de deportación por la cancelación del DACA.

A lo largo de seis partes Carlos Fuentes presenta el ensayo de Rodó como un hito del pensamiento latinoamericano, valora sus aciertos, sus limitaciones y también señala sus errores. Aun reconociendo que su estilo tuvo el mayor predicamento entre las nuevas generaciones del siglo XX, empieza por condenar la "insufrible" prosa de Rodó y sus "florituras retóricas", y, por eso (para espanto de filólogos puristas) celebra la versión realizada por la traductora Margaret Sayers Paden, donde se han eliminado "los excesos" y "la locura" estilística de Rodó a favor de una mayor sobriedad expresiva. Esta opinión de Fuentes sobre un estilo que fascinó a Alfonso Reyes, puede tomarse como una cortesía hacia los alumnos extranjeros del siglo XXI, pero no deja de chocar con el criterio de otros autores actuales como Adolfo Castañón, que en su artículo "Rondando a Rodó en su Ariel" (2003: 154), se refirió a sus "páginas cinceladas con plástica precisión". Cuestión de gustos, podrá decirse, o divergencia de criterios sobre la forma de hacer digeribles las obras clásicas, pero la posición de José Luis Martínez sería decisiva y convincente en este debate, cuando afirmaba que "el arte de decir" formaba parte del plan rodoniano de integración por la cultura, y que ese estilo, como sus imágenes, "son la trama de la conciencia cultural e histórica, de la identidad” (2001 I, 432). 
A continuación Fuentes se pregunta: "iPor qué entonces el insoportable Rodó?" (1988: 15). Aquí empieza su viva exposición sobre la importancia de Ariel en el contexto histórico en que fue escrito por su ataque a la nordomanía que profesaban los liberales latinoamericanos. La obra de Rodó, precisa Fuentes, fue una respuesta política y emocional de América Latina a esa situación; una utopía cosmopolita inspirada en los valores republicanos y nacionalistas de Francia y en la democracia de la antigua Grecia - a través de Francia y de El nacimiento de la tragedia de Nietzsche (y de Schiller). Pero Fuentes observa que Rodó no proponía una ciega imitación de los modelos, sino la selección y adaptación de lo más valioso y acorde con el medio americano. Así vislumbra en el cosmopolitismo de Ariel el respeto a las tradiciones locales, la "fidelidad al pasado" y a sus "fuerzas formativas", lo que equivale en su opinión al esbozo de una "totalidad plural" heterogénea y polifacética (15).

Esa idea de Ariel es la que le interesa aprovechar a Fuentes para completarla y proyectarla hacia el futuro: "Si, como yo creo, América Latina ya ha conseguido una identidad, entonces debe pasar la prueba de vivir con la alteridad" (15), y propone extrapolar esta idea en términos políticos y económicos: "debemos pasar del nacionalismo a la interdependencia", pero a una interdependencia entre naciones libres, pues si alguna fuera dependiente, estaría condenada a ser colonia o protectorado. Obviamente, Fuentes tiene a la vista el reciente ingreso de México al Tratado Internacional de Libre Comercio, firmado en 1992 y activado en 1994. En el plano cultural -propone Fuentes - también habrá que poner a prueba la identidad nacional en las aguas de la alteridad, porque "El Otro nos define" (16). ${ }^{12}$ Pero esa identidad dialógica, en un mundo donde los valores tradicionales se fragmentan, no podrá ser ya homogénea y centrípeta, sino heterogénea y centrífuga; y así, recurre a su fecunda lectura de Bajtin, Adorno y Max Weber (con su "politeísmo de los valores") para indicar la

12 Sobre esta definición de la identidad como encuentro dialéctico con los otros es imposible no recordar el influyente ensayo de Octavio Paz sobre México, El laberinto de la soledad (1950) o el poema "Piedra de Sol" (1957). 
riqueza que aporta al mundo la diversidad y lo heterogéneo. Será entonces una identidad dinámica, en proceso, porque una identidad estática y cerrada sólo significa que estamos incompletos. De este modo, frente a los dogmas de las instituciones cristalizadas en rígidas jerarquías, la sociedad civil contemporánea es la que avanzará hacia esa identidad abierta a lo otro, en constante creatividad.

Por eso Fuentes le reprocha a Rodó el haber elegido en 1900 una sola de las opciones de la identidad de América Latina, despreciando otros muchos aspectos de la cultura latinoamericana: "Apenas hay un aliento de la cultura india, del pensamiento agustiniano y tomista (políticamente tan poderoso en América Latina), o del utopismo renacentista" (17), como tampoco hay nada del Barroco y de la mística española. Además, en su dependencia de Europa, Rodó también absorbió unos valores estéticos ya desfasados que se fundan en un concepto platónico de Belleza asociada a lo Bueno y lo Justo o Verdadero. Afirma que contra esta concepción estética, que inspiró el estilo rodoniano, reaccionaron los escritores de su generación, como los grandes poetas: Neruda, poeta de la vida cotidiana; Vallejo, que "lanzó una piedra ciega de ira y desesperación en el cristal perfectamente enmarcado de Rodó"; Borges, con su reducción de la prosa a lo esencial. Ellos hicieron desaparecer "la espiritualidad de alto vuelo de Rodó" (17).

Fuentes declara que "venimos de una reacción contra Rodó", pero añade que incluso con su retórica florida y su espiritualidad alada, sus ideas siguen abiertas a una relación dialéctica: "cumplen la función de la tesis a la que podremos presentar nuestra antítesis" (18); y si esa confrontación es posible, es porque Rodó fue honesto al no haber pretendido imponer una definición dogmática y exclusiva de la identidad latina. ${ }^{13}$ Incluso el prologuista de Ariel aprueba su idea de una élite intelectual nacida de la democracia misma, porque no se trata de una aristocracia basada en anacrónicos privilegios hereditarios, sino del crecimiento de lo selecto a partir de la igualdad de oportunidades.

13 Cfr. Valiente Mundo Nuevo (1990: 279) donde Fuentes propondrá el concepto identitario más incluyente de Indoafroiberoamérica. 
Sin embargo, Fuentes no comparte el énfasis que puso Rodó en elevar lo espiritual sobre lo utilitario y prefiere el equilibrio entre el progreso utilitario y el de las ideas en una democracia progresista que, además, siempre debe ser reformada y mejorada para que no se desvirtúe su sentido. Este asunto, del mayor interés en el pensamiento de Carlos Fuentes, lo conduce a revisar la crítica rodoniana a la democracia de Estados Unidos.

Fuentes le otorga a Rodó el acierto de haber sabido caracterizar algunos rasgos positivos del pueblo gringo: su grandeza por el poder dignificante que otorgan al trabajo, su espíritu de asociación, su filantropía y entrega a la investigación y a la industria; su reverencia por la educación pública y su habilidad prodigiosa para la improvisación. "Rara vez se ha ofrecido un cuadro tan brillante de las virtudes norteamericanas, especialmente por parte de un latinoamericano" - añade-, a pesar de que no le parecía que Rodó estuviera bien versado en la literatura norteamericana (como ya lo había hecho notar Pedro Henríquez Ureña). También acepta Fuentes la pertinencia y actualidad de muchas objeciones de Rodó a los vecinos del norte, como las relativas a su acumulación de información, que no significa sabiduría; la falta de una selección de los mejores, sin que esta dañe la igualdad democrática; la cultura del bienestar, que no garantiza la nobleza de un destino; o "la maravillosa energía que es la característica suprema de los gringos", pero que se consume en su fuerza expansiva sin alcanzar aquellas "exigencias legítimas de la dignidad intelectual y moral" que Rodó reclamaba (20).

A diferencia de Rodó, que admiraba a Estados Unidos, pero no los amaba, Carlos Fuentes declara admirarlos y amarlos, pero desde esos sentimientos y un diplomático respeto, critica la política estadounidense contemporánea y su pretensión de realizar la "conquista moral" de la América Latina y del mundo que, como supo advertir Rodó, tentó a tantos a la imitación, cuando el modelo carecía de fundamentos culturales, políticos o incluso económicos adecuados para sostener su prestigio fuera de sus fronteras. Fuentes considera con Rodó que si las superpotencias son poderosas solo porque están fuertemente armadas, esa fuerza oculta "una forma lamentable de debilidad". En virtud de ese argumento, cree que 
"Rodó, sin saberlo, anunció una era de diversificación política y cultural", donde es impensable una cultura absoluta y una política absoluta (21). Por eso recuerda las críticas de Rodó al chauvinismo estadounidense y a su infantil competencia con Europa, cuando afirmaba que el mérito de Estados Unidos no es tan grande como para situar el eje del mundo en su nuevo Capitolio.

Reconocidos los aciertos, Fuentes cree que Rodó se equivocó al decir que los norteamericanos carecían del genio de la persuasión y de la vocación del apóstol para conquistar la hegemonía mundial. Podrían tenerla, opina, si no se la negaran a sí mismos por la incongruencia de su doble conducta: democrática en su política interior, pero imperialista en su política exterior, pese a que traten de convencer al mundo de que exportan su democracia a otros países necesitados de ella (23). Poco antes de la Guerra del Golfo, Fuentes toma como ejemplo la política de Estados Unidos en Nicaragua y en Irán para denunciar la ilegitimidad de sus métodos, tanto al alinearse con regímenes antidemocráticos como el de Somoza en Nicaragua y el del Shah en Irán, como al intervenir contra las naciones más débiles (a veces con su fuerza militar), violando el derecho internacional, los derechos humanos y el respeto a otras naciones que no comparten sus valores culturales. Al cuestionar las relaciones internacionales de Estados Unidos con México, Fuentes subraya que los mexicanos, por su vecindad, son los primeros extranjeros, los primeros otros a quienes los gringos deben conocer y comprender, porque "somos los Otros en la puerta, no en el patio trasero, en una casa que tiene su nombre, dimensiones, diseño, estilo y propósitos: América Latina" (25).

Por otra parte, Fuentes lamenta que Rodó no hubiera acompañado su crítica a Estados Unidos con otra a la cultura de América Latina, con lo que Ariel habría sido un libro diferente. Al imaginar la comparación que Rodó no hizo, supone que hubiera llegado a conclusiones similares: norteamericanos y latinoamericanos "somos proyectos de historia, sociedades incompletas, modelos de trabajo, no paradigmas de perfección" (24). Desde su posición socialdemócrata, Fuentes describiría ese trabajo como el enorme esfuerzo de un Sísifo colectivo para salvaguardar la identidad cultural 
de Iberoamérica y sincronizarla con proyectos de estado donde la justicia propicie una vida verdaderamente democrática, integradora y cooperativa, para limar así las desigualdades que hoy dividen al mundo (Fuentes 1994: 87-96).

Por último, Fuentes lamentaba también que Rodó no desarrollara algo más su intuición sobre los problemas que la inmigración europea masiva estaba generando en la identidad de las nuevas democracias latinoamericanas, cuando en el Río de la Plata de 1900 ya disponía de la experiencia social y cultural para hacerlo. La situación le parecía equiparable a la de Estados Unidos en la actualidad,

[A] medida que la sociedad civil homogénea de los Estados Unidos se enfrenta a la inmigración de lo inmensamente heterogéneo y, lo que es aún peor, de lo próximo [América Latina], enfrentamos el desafío de una sociedad civil heterogénea invadiendo antiguos espacios homogéneos del poder político, militar y religioso (Fuentes 1988: 25).

Pero ante esa realidad añade que "el destino de nuestras respectivas sociedades civiles es mucho más importante que los duelos entre nuestros estados nacionales" (25).

Como vemos, Carlos Fuentes escribió un ensayo sobre Ariel que, en ciertos aspectos, ofrece una reescritura crítica y un apasionado diálogo intertextual. Este cruce de perspectivas, la del uruguayo de 1900 y la del mexicano de 1988, se produce sobre todo en torno a la crítica a Estados Unidos, pero, pese a todas sus objeciones, demuestra que Ariel resiste todavía una vigorosa relectura contemporánea.

Sin embargo, también podemos sentir los huecos que Fuentes dejó en su texto; por ejemplo, su silencio en torno a la oposición simbólica entre Ariel / Calibán y al protagonismo que éste obtuvo en los estudios culturales y postcoloniales a partir del ensayo Calibán de Roberto Fernández Retamar (1971). En la primera edición de su libro el poeta, crítico e ideólogo de la Revolución Cubana no solo había declarado que el isleño Calibán representaba mejor que Ariel al latinoamericano colonizado, sino que también, a raíz del escándalo internacional suscitado por el encarcela- 
miento y proceso del poeta Heberto Padilla, dedicó un fuerte ataque a los intelectuales que criticaron los métodos represivos del régimen de Fidel Castro contra la libertad de expresión. Carlos Fuentes, como José Revueltas y Carlos Monsiváis, había firmado la célebre carta de protesta que unos sesenta intelectuales de distintos países dirigieron a Fidel Castro. ${ }^{14}$ En la pasión furibunda de aquellas páginas, Fuentes aparecía caricaturizado como el cabecilla de "la mafia mexicana" que retiró su apoyo a la Revolución y, además, como un peligroso escritor y crítico contrarrevolucionario que colaboraba en la revista Mundo Nuevo, financiada por la CIA (Fernández Retamar 1971: 64-69). Pero es muy posible que, de la misma manera que en 1993 Fernández Retamar quiso dejar atrás aquella controversia y al mismo Calibán, también Fuentes quisiera dar por agotado aquel asunto, que abrió una brecha profunda en la intelectualidad latinoamericana de los años setenta. ${ }^{15}$ Unos años más tarde sí abordaría de manera testimonial ese espinoso debate Carlos Monsiváis en Aires de familia.

III

Aires de familia. Cultura y sociedad en América Latina, de Carlos Monsiváis, fue premiado en el concurso de la editorial Anagrama de Barcelona y se publicó en esa misma editorial en el año 2000. La fecha es simbólica, no solo porque marcaba el cambio de milenio, sino también porque, al celebrarse el centenario de la publicación de Ariel, se produjo en varias universidades latinoamericanas y europeas una relectura crítica del ensayo y del arielismo, al tiempo que los estudios culturales, postcoloniales y subalternistas negaban la idea de una identidad homogénea y armoniosa, para atender más bien a los elementos diferenciales y no asimilables al conjunto; a los sectores excluidos que reclamaban su inclusión en una

14 El dato sobre la firma de la carta por Monsiváis lo ofrece Enrique Krauze en su detallada relación de aquellos acontecimientos en Redentores (2011: 407).

15 Véase "Postdata de enero de 1993". Fernández Retamar 2014: 72-81. 
totalidad democrática más justa, polifónica y heterogénea. El ensayo de Monsiváis, donde Rodó solo aparece como una luz muy lejana, expresa esas inquietudes, pero, en tanto discurso fragmentario sobre la identidad latinoamericana y sobre la necesidad del intelectual crítico en las democracias, todavía guarda relación con esas ideas-fuerza postuladas cien años antes en Ariel. Sin embargo, la mediación social del intelectual letrado también estaba en entredicho, como planteó certeramente Beatriz Sarlo en "Intelectuales" (1994: 180), pues, entre el fracaso educativo de la escuela y los subproductos culturales que sirven los medios, "los gestos heroicos del intelectual santo o profeta, suenan especialmente fuera de ritmo con la melodía asordinada de la época". Pero si la ensayista argentina creía que no todo estaba perdido, y que los nuevos intelectuales podrían llagar a hacerse oír, quizás pensaba en el poder comunicativo del prodigioso recreador de la crónica literaria, crítico cultural y ensayista Carlos Monsiváis.

En su libro - ensayo de ensayos o mosaico intertextual- ${ }^{16}$ Carlos Monsiváis organizó en siete partes su visión problematizada de la cultura mexicana y latinoamericana, en tiempos tan hostiles para emitir juicios tradicionales sobre la identidad cultural como los del neoliberalismo, la globalización tecnológica y el ingreso de México al TLCAN. Su ensayo contempla la progresiva hipertrofia materialista e individualista de las nuevas democracias latinas del siglo xx y, a diferencia de Ariel, no puede ser del todo optimista. Pero, como advierte Linda Egan, Monsiváis no atacaba directamente al neocapitalismo transnacional de Estados Unidos:

Lo que más obviamente va revelándose es su desprecio contundente por los efectos nefastos de la globalización sobre los medios masivos y el homenaje que universalmente se rinde a la tecnología. Se diría que este proceso - del que el neoliberalismo es a la vez productor y producto - casi ha desvirtuado el proyecto civilizatorio que Monsiváis persiguió durante más de cinco décadas (Egan 2013: 498).

16 En su libro sobre Monsiváis, Linda Egan se refiere a esa intertextualidad como al reciclaje de algunos textos o fragmentos de textos ya publicados desde 1979, pero que, reificados, se ofrecen a una nueva situación de lectura o "metalectura", así como a la experiencia de nuevos lectores (2013: 416-417). 
En ese clima poco alentador, muertas las utopías del progreso indefinido de la Modernidad en democracias insolidarias y con rasgos aún premodernos (pobreza, analfabetismo) todavía pendientes de resolución, Monsiváis se muestra como el creador de un tipo de ensayo nuevo, "proteico", sobre lo mexicano y lo latinoamericano -cada vez más deslatinizado por la presión mediática del consumo globalizado.

Monsiváis evita el tono didáctico de Ariel, la exposición histórica de Krauze y la esgrima del prólogo de Fuentes, y se sumerge en una realidad barroca y caótica, poniendo en juego sus ingeniosos recursos típicamente postmodernos: la paradoja, el humor, el sarcasmo y la ironía atraviesan su gran acopio de saber literario e información objetiva, que el autor va interpretando a la luz de una historia de los sentimientos y pulsiones del imaginario popular hispanoamericano en su tensa relación con la cultura letrada. De este modo, Monsiváis renueva la forma del ensayo para hacer de él un espacio habitable por un pensamiento que, lejos de pretender atrapar una esencia identitaria cristalizada o predefinida, expone la complejidad y las incertidumbres de la vida latinoamericana contemporánea. En los primeros capítulos le interesa mostrar los reflejos del pueblo en las representaciones letradas y yuxtaponerlas con sus propias manifestaciones colectivas en la cultura popular y los acontecimientos de masas. De esta forma los grandes temas históricos, así como los héroes sacralizados del siglo XIX y los grandes discursos culturales de la patria, o la identidad que Rodó contribuyó a definir, conviven en fecunda promiscuidad con las películas de Cantinflas y de Jorge Negrete, con los melodramas, con la contracultura, con los polémicos programas de Cristina en Televisa, salteados con anécdotas de muy diversa procedencia.

Porque, buscando esos "aires de familia" a través de las permanencias y mutaciones que fue experimentando la idea de identidad latinoamericana, y más allá de la inclusión del otro un tanto general que demandaba Carlos Fuentes, Monsiváis da con las identidades excluidas, terreno en que él mismo militó como un activista a favor de las minorías marginadas. Su sondeo de la identidad, decididamente abierta a lo popular, atenderá a aquellas representaciones de sus hablas y sus músicas en novelas como 
Tres tristes tigres o La guaracha del macho Camacho, y a los reflejos del imaginario emocional del cine en las novelas de Manuel Puig.

Pero la televisión comercial e Internet aparecen problematizados: si bien estos medios de comunicación masiva permiten liberar y reflejar sin aparente censura sentimientos colectivos que hermanan a una gran colectividad, Monsiváis observa que, a través de ellos también se modelan y mediatizan los deseos de millones de telespectadores-consumidores, a quienes se les infiltra nuevas formas subliminales de dominación que fomentan el individualismo y disuelven su conciencia de pertenencia a una comunidad cultural.

El horizonte confuso que contempla al final de su ensayo es el de la posmodernidad, con la cara más negativa de la globalización, aliada a la expansión planetaria de Internet y agravada por la movilidad y deslocalización que implican las migraciones, tanto las físicas a través de las fronteras, como las de los roles sociales, sexuales y de las costumbres. Pero en ese panorama fluido, inabarcable al análisis y de efectos imprevisibles, Monsiváis vislumbraba alguna esperanza. Todos los valores dados como sólidos y estables, aprisionados bajo etiquetas ortopédicas, empezaban también a liberarse, como "las identidades carcelarias de lo masculino y lo femenino" (2000: 175), y en ciertos focos activos de la sociedad civil se encendía una nueva conciencia crítica. Pero los "profetas del nuevo mundo" ya no podrán ser para Monsiváis aquellos "santos laicos" liberales de principios de siglo, como Rodó o Vasconcelos, por los que el espíritu hablaba a las reducidas élites universitarias, excluyendo a indios, mujeres y homosexuales. Por el contrario, serán aquellos que

[...] estimulan en sectores significativos la búsqueda de ideales desprejuiciados, defienden y argumentan los otros modos de ser y de pensar, le consiguen el espacio posible a la diversidad y a la noción de futuro que cabe y se expande en los actos y los pensamientos disidentes (181).

Lejos de todo triunfalismo, Monsiváis no oculta los factores negativos que también, como invariables históricas agravadas en las sociedades capitalistas, contribuyen a formar y deformar la identidad latinoamericana: 
la deuda externa, la desigualdad, el desempleo, el analfabetismo funcional de una gran parte de la población; en suma: la imperfección e injusticia de las democracias neoliberales que los héroes culturales de principios de siglo, como Rodó, no pudieron ni sospechar, cuando pensaban que las nuevas democracias latinas avanzarían integradas por la educación, la voluntad y el estudio, gracias a la guía de intelectuales tolerantes y en constante autoeducación, que propagarían la luz ideal y fraterna de su evangelio laico.

Pero, como vemos, el lugar de enunciación de Monsiváis se encuentra más bien entre aquella "áspera muchedumbre" urbana que los discípulos iniciados por el profesor que apodaban Próspero encontraron con mal disimulado desagrado al salir del aula a la calle, en los párrafos finales de Ariel. Ese parece ser el lugar del desencanto y de la esperanza no del todo vencida, donde Monsiváis quiso situarse, como intelectual de izquierdas en una posmodernidad que se resiste a admitir la derrota de un humanismo crítico y liberador, enfrentado no solo al poder, sino también a los nuevos poderes ubicuos que gobiernan el mercado multinacional de la tecnología y la economía del conocimiento.

Llegados al fin del recorrido por estos tres ensayos, focalizados únicamente en Ariel y, particularmente, en la polaridad Estados Unidos-América Latina, podemos concluir que, si algo presentan en común, es el reconocimiento de Ariel como el discurso fundacional sobre la identidad hispanoamericana en su oposición a Estados Unidos y, en otro orden, la capacidad del breve ensayo de Rodó para seguir interesando a intelectuales contemporáneos de diversa orientación ideológica como un documento de imprescindible referencia. En esta situación, los matices que aportan nuestros tres ensayistas presentan cierta unanimidad en los aspectos más externos, pero también la fricción de sus puntos de vista ante el destino incierto de las identidades latinoamericanas. En la actualidad muchos de los argumentos de Rodó han sido superados y ni siquiera resulta válido ya un concepto de identidad monolítico, estático y excluyente. Aun así, pese a los cambios de perspectiva y la resonante polifonía de los discursos en el cambio de milenio, el ensayo de Rodó no solo sigue en pie como libro canónico y como referencia histórica ineludible, sino que, a través de las 
relecturas que suscita, consigue revivir y encender cada vez luces nuevas en la "inteligencia americana".

BIBLIOGRAFÍA

CASTAÑÓn, ADOlfo. "Rondando a Rodó en su Ariel". Istor v. 17 (verano 2004): 154-161. Artículo en línea disponible en www.istor.cide.edu/ istor.html. (Consultado el 12 de septiembre de 2017).

EGAN, Linda. Leyendo a Monsiváis. México: unam. 2013 (Serie El Estudio). Frugoni, Emilio. "Ariel en el momento de su aparición". Homenaje a Rodó en el Cincuentenario de Ariel. Reproducido en El libro de los elogios. Montevideo, 1953. 205-212. Artículo en línea disponible en http://www.autoresdeluruguay.uy/biblioteca/Jose_Enrique_Rodo... (Consultado el 13 de octubre de 2017).

FERNÁNDEZ ReTAMAR, RoBerTo. Calibán y otros ensayos. La Habana: Arte y Literatura, 1979.

Fuentes, Carlos. "Prologue". J. E. Rodó. Ariel. Margaret Sayers Peden translation, Reader's Reference and Annotated Bibiography. Austin: University of Texas Press, 1988.

Valiente mundo nuevo. Épica, utopía y mito en la novela bispanoamericana. Madrid: Mondadori, 1990.

"Después de la Guerra Fría: los problemas del nuevo orden mundial". Tres discursos para dos aldeas. México: FCE, 1994.

KraUZE, ENRIQue. "La invención de Ariel". Istor IV. 15 (invierno 2003): 138-

142. Artículo en línea disponible en www.istor.cide.edu/istor.html (Consultado el 25 de agosto de 2017).

"José Enrique Rodó. La homilía hispanoamericana". Redentores. Ideas y poder en América Latina. Barcelona: Debate, 2011. 41-63.

MarTínez, José Luis (comp.). El ensayo mexicano moderno (I). México: FCE, 2001. $3^{\mathrm{a}} \mathrm{ed}$. 
MonsIváIS, Carlos. Aires de familia. Cultura y sociedad en América Latina. Barcelona: Anagrama, 2000.

Rodó, José EnRIQue. Obras completas. Emir Rodríguez Monegal edición, introducción, prólogo y notas. Madrid: Aguilar, 1967.

SARLO, BEATRIZ. Escenas de la vida posmoderna. Intelectuales, arte y videocultura en la Argentina. Buenos Aires: Ariel, 1994.

Varela Petito, GonZalo. "Ariel en su centenario". Leopoldo Zea y Hernán Taboada (comps.). Arielismo y globalización. México: Instituto Panamericano de Geografía e Historia/FCE, 2002.

ZEA, LEOPOLDO. "Ariel, un siglo después", en Leopoldo Zea y Hernán Taboada (comps.). Arielismo y globalización. México: Instituto Panamericano de Geografía e Historia/FCE, 2002. 